\title{
OBSERVATÓRIO DE CONFLITOS URBANOS DE CURITIBA: METODOLOGIA E CATEGORIAS DE ANÁLISE
}

\author{
José Ricardo Vargas de Faria* \\ Simone Aparecida Polli** \\ Ramon José Gusso*** \\ *Universidade Federal do Paraná, Centro de Estudos em Planejamento e Políticas Urbanas, Curitiba, PR, Brasil \\ ** Universidade Tecnológica Federal do Paraná, Programa de Pós-graduação em Planejamento e Governança \\ Pública, Curitiba, PR, Brasil \\ ${ }^{* \star \star}$ Instituto Federal de Brasília, Curso Superior de Tecnologia em Gestão Pública, Brasília, DF, Brasil
}

\begin{abstract}
Resumo
Os conflitos urbanos, como expressão da conflitualidade social, são fenômenos importantes e objeto destacado para a reflexão sobre as dinâmicas e relações sociais. A proposta deste trabalho é apresentar categorias e metodologia que contribuam para aprofundar o conhecimento sobre as lutas sociais urbanas e sua inserção na dinâmica mais geral da conflitualidade social, com base na experiência de construção de instrumentos de pesquisa e aportes teóricos que subsidiam o Observatório de Conflitos Urbanos de Curitiba. A análise global dos 707 protestos registrados traz elementos para avaliação do potencial teórico-metodológico da proposta, evidenciando que os protestos acionam, de diferentes maneiras, demandas pela qualificação (melhorias em infraestrutura e serviços), apropriação (reconhecimento de usos) e transformação (modificação dos processos de produção) dos espaços urbanos.

Palavras-chave

Conflitos Urbanos; Metodologia; Ação Coletiva; Protestos; Curitiba.
\end{abstract}




\title{
THE CURITIBA OBSERVATORY OF URBAN CONFLICT: METHODOLOGY AND ANALYTICAL CATEGORIES
}

\author{
José Ricardo Vargas de Faria* \\ Simone Aparecida Polli** \\ Ramon José Gusso*** \\ *Universidade Federal do Paraná, Centro de Estudos em Planejamento e Políticas Urbanas, Curitiba, PR, Brazil \\ **Universidade Tecnológica Federal do Paraná, Programa de Pós-graduação em Planejamento e Governança \\ Pública, Curitiba, PR, Brazil \\ ***xInstituto Federal de Brasília, Curso Superior de Tecnologia em Gestão Pública, Brasília, DF, Brazil
}

\begin{abstract}
Urban conflicts, as an expression of social conflict, are significant phenomena and represent a prominent object for reflection on social dynamics and relations. The aim of this paper is to present categories and methodology that help to broaden knowledge on urban social struggles and their insertion into the most general range of social conflict based on the experience of building research instruments and theoretical contributions that contribute to the Curitiba Observatory of Urban Conflict. The global analysis of the 707 documented protests delivers elements with which to assess the theoretical-methodological potential of the proposal, thereby indicating that the protests, in different ways, have triggered demands for the qualification (improvements in infrastructure and services), appropriation (recognition of uses) and transformation (modification in production processes) of urban spaces.
\end{abstract}

Keywords

Urban Conflicts; Methodology; Collective Action; Protests; Curitiba 


\section{OBSERVATÓRIO DE CONFLITOS URBANOS DE CURITIBA: METODOLOGIA E CATEGORIAS DE ANÁLISE}

José Ricardo Vargas de Faria

Simone Aparecida Polli

Ramon José Gusso

Introdução

A praça Santos Andrade recebeu o ato "Greve Global pelo Clima” contra a degradação ambiental na Amazônia. No dia 7 de setembro, as ruas de Curitiba foram tomadas por mais um ato do "Tsunami da Educação". Protesto contra a morte de jovens no bairro Parolin. Servidores municipais mobilizam-se contra o "Pacote de Greca”. Ato em solidariedade a vítimas de homofobia.

Não fossem os personagens e as localidades que particularizam essas notícias, os discursos e imagens que acionam seriam universais. Os conflitos são recorrentes nas mais diversas formações sociais e, por isso mesmo, tornam-se objeto privilegiado de investigação nas Ciências Sociais e Políticas apoiando-se em recortes epistemológicos distintos: como chave de interpretação das sociedades e como disfunções sistêmicas. Embora não se encerrem nas formas manifestas, os conflitos têm nos protestos uma forma de expressão empírica. O GDELT Project (Base de Dados Global de Eventos, Linguagem e Tons), que registra notícias veiculadas na imprensa mundial em mais de cem idiomas desde 1979, contabiliza 1,3 milhão de eventos de protesto no mundo, com crescimento expressivo nos últimos anos. Beieler (2015) reconhece, porém, que o crescimento do número de registros se deve, em parte, à ampliação do acesso às informações proporcionado pela digitalização das notícias e pela disseminação propiciada pela internet (GDELT, 2015; BEIELER, 2015).

Apesar da diversidade de espaços, tempos, contextos e objetos, é inegável que a cidade, em particular, tem sido palco privilegiado das lutas e manifestações 
sociais. Ocupações de espaços públicos, fechamento de vias e depredação de monumentos, edificações públicas ou privadas são apenas algumas formas pelas quais as lutas se manifestam. Acontecem na cidade porque a forma específica do capitalismo é a forma urbana. Restringir a cidade, contudo, ao palco ou ao continente das lutas é negligenciar outras dimensões: a cidade como objeto de disputa, a cidade como estrutura estruturada e estruturante dos conflitos sociais e, principalmente, a cidade como conteúdo das lutas.

Compatibilizar a análise dos conflitos urbanos com a análise do próprio processo de urbanização e, mais especificamente, do processo de produção capitalista das cidades, no entanto, não é tarefa teórica simples. Interpretações críticas mais tradicionais sobre os conflitos sociais no capitalismo com frequência subvalorizaram a importância dos conflitos urbanos (e, em consequência, os secundarizam analiticamente), subordinando-os ao campo da condição de reprodução do trabalho e destituídos do potencial transformador ou revolucionário que teriam as lutas pela tomada do poder de Estado ou pela apropriação dos meios de produção. Uma interpretação meramente estruturalista sobre as lutas urbanas seria uma atividade ociosa, pois a resposta sobre a gênese das mobilizações, bem como o significado do conteúdo que tais reivindicações ou protestos anunciam, estaria dada de antemão pela teoria, com o resultado inelutável da dinâmica global das cidades no capitalismo. Por outro lado, as teorias dos movimentos sociais, constituídas no confronto a essa teleologia das classes sociais, ao mesmo tempo que valorizam a organização política, a identidade dos agentes e a ação coletiva em si mesma, incorrem muitas vezes em uma interpretação fenomenológica dos conflitos sociais, dissociando-os da compreensão dos processos de reprodução social.

O projeto de pesquisa Observatório de Conflitos Urbanos de Curitiba', iniciado em 2013 - que tem como objetivo registrar, sistematizar, classificar e prover informações sobre lutas urbanas, movimentos sociais e as múltiplas e diversas manifestações da conflitualidade da cidade, por meio de uma base de dados georreferenciada online ${ }^{2}$-, se inscreve em um esforço de aprofundar a compreensão sobre as condições materiais e os processos políticos que incitam conflitos urbanos.

Os conflitos urbanos, objeto de análise, são definidos como confrontos ou litígios, manifestos ou não, relativos às condições de vida urbana, que reivindiquem

\footnotetext{
1. Essa pesquisa foi financiada pelo Conselho Nacional de Desenvolvimento Científico e Tecnológico (CNPq), Chamada Ciências Humanas e Sociais MCTI/CNPq/MEC/Capes n. 22/2014, número do processo 471911/2014-3, período 2015-2017, e pela Chamada Universal MCTI/CNPq n. 01/2016, número do processo 432856/2016-1, período 2017-2021.

2. A base de dados está disponível online para pesquisadores cadastrados. Para consulta sobre sínteses dos levantamentos mensais, ver http://conflitoscuritiba.blog.br.
} 
reconhecimento ou incidam sobre a produção e/ou o consumo da cidade, opondo pelo menos dois agentes sociais. Para efeito deste trabalho, os protestos urbanos são suas manifestações empíricas e seu georreferenciamento permite sobrepor informações acerca das condições urbanas nas quais os conflitos emergem, como acesso aos serviços e infraestruturas públicas, por exemplo.

A pesquisa integra a Rede de Observatórios de Conflitos Urbanos, uma iniciativa de diversos grupos de pesquisa nacionais e internacionais, que tem como um dos pontos de partida o projeto Mapa dos Conflitos Urbanos do Rio de Janeiro, desenvolvido a partir de 2004 pelo laboratório Estado, Trabalho, Território e Natureza (Ettern) do Instituto de Pesquisa e Planejamento Urbano e Regional (Ippur) da Universidade Federal do Rio de Janeiro. Atualmente, envolve diversas cidades, como Belo Horizonte (MG), Maceió (AL), São Paulo (SP), Porto Alegre (RS), Quebec (Canadá), Cidade do México, Los Angeles (Estados Unidos), Medellín (Colômbia), Buenos Aires (Argentina) e Santiago do Chile.

Seguindo a experiência desenvolvida no projeto Mapa dos Conflitos Urbanos do Rio de Janeiro se iniciaram o registro e o mapeamento dos conflitos urbanos em Curitiba utilizando como base algumas categorias, como o objeto, a forma de manifestação, os agentes, o local (de origem e de manifestação) e a data de ocorrência dos conflitos. As informações foram obtidas, principalmente, em registros de jornais diários de grande circulação, portais de notícia, rádios, redes sociais, jornais locais e mídia independente, com o objetivo de identificar manifestações públicas e obter informações básicas sobre os conflitos urbanos em Curitiba e Aglomerado Metropolitano. Procurando minimizar os possíveis vieses das notícias, foram realizadas triangulações de fontes jornalísticas e os dados básicos foram complementados com informações de redes sociais dos agentes, pesquisas de localização em mapas e imagens na web, assim como por meio de observações diretas.

Este artigo apresenta elementos teóricos que indicam a revisão da metodologia inicialmente utilizada pela Rede de Observatórios de Conflitos, além da análise dos conflitos registrados entre 2013 e 2017 na Região Metropolitana de Curitiba (RMC), já considerando as novas categorias propostas. Além desta introdução e da conclusão, está estruturado em três itens. No primeiro, apresenta uma breve problematização teórica sobre os conflitos urbanos, apontando os elementos a serem considerados na sua análise. O segundo tópico aborda as questões metodológicas, desde o design inicial da pesquisa até as formulações mais acabadas, que indicam as categorias e a estrutura metodológica para o registro e o mapeamento dos conflitos urbanos. No terceiro item, são discutidos os resultados da análise dos dados sistematizados entre 2013 e 2017. Na conclusão, apresentam-se os principais 
achados da pesquisa e se reitera a necessidade de incorporação de categorias para a análise de eventos de protestos em que a cidade não é apenas palco, mas objeto dessas ações.

1. Os conflitos sociais e urbanos como chave de interpretação das relações sociais

O conflito é uma forma de sociação, uma interação que, segundo Simmel (2011, p. 567), está entre as mais vívidas e destinadas a causar ou modificar grupos de interesse, unificações ou organizações. Categoria sociológica e filosófica fundamental em diferentes interpretações das relações sociais, o conflito adquire na dialética um posto privilegiado, o de motor da história, segundo a teoria marxista. Para Marx e Engels (1999, p. 40) "a história de todas as sociedades até hoje existentes é a história da luta de classes”.

Na tradição marxista, entretanto, há uma tendência a conferir centralidade ao conflito que opõe classes sociais determinadas por sua inserção nas relações sociais de produção, eventualmente relevando o papel transformador de conflitos que não estejam inscritos nessa condição. Os movimentos urbanos são secundarizados, pois o gérmen da transformação reside na classe trabalhadora, no proletariado, como sujeito privilegiado. A condição urbana dessa classe é acessória ${ }^{3}$ e é a relação de exploração do trabalho pelo capital que, em última instância, deve ser superada. Desde Engels (2008), em sua análise sobre a situação da classe trabalhadora na Inglaterra, a condição insalubre e precária da vida na cidade é a expressão da dominação de classe, cujo remédio é o fim da propriedade privada e a apropriação coletiva dos meios de produção pelo proletariado. Em outro texto, sobre a questão da habitação (ENGELS, 2015), a propriedade da moradia pelo trabalhador, em vez de avanço, é compreendida, em certa medida, como retrocesso no processo revolucionário, como solução burguesa para a questão e, portanto, como não solução, já que o problema é insolúvel nos marcos do capitalismo.

Os efeitos dessas interpretações se fazem sentir ainda hoje, na medida em que algumas análises sobre os movimentos sociais urbanos questionam seu caráter classista ou transformador, caracterizando-os como "meras tentativas reformistas de lidar com questões específicas (e não sistêmicas)” (HARVEY, 2014, p. 17). Há, no entanto, um campo do pensamento marxista que, pelo menos desde meados da década de 1960, com Lefebvre (2006), discute o direito à cidade com base na ideia

3. É conhecida a polêmica com Lênin sobre a quem caberia conduzir o processo revolucionário, desconfiando do papel do campesinato em favor da classe operária urbano-industrial. Essa polêmica residia muito mais na inserção de cada classe no processo de produção (classe objetiva) do que na sua territorialidade, mesmo que sejam elementos indissociáveis. 
de um conteúdo urbano das lutas sociais: além de palco, a cidade é modo de vida, objeto de lutas e substrato da organização social. Esse campo de pensamento ganha expressão com autores como Castells, Borja, Lojkine (FORTI, 1979; MOISÉS, 1982; HARVEY, 2014) e outros que problematizam a importância da urbanização no ciclo de reprodução do capital (TOPALOV, 1979), com forte repercussão na sociologia urbana brasileira das décadas de 1970 e 1980. Destaca-se o conceito de espoliação urbana, mobilizado por Lúcio Kowarick (1979), a condição de subcidadania dos trabalhadores com baixos salários, ao não acessarem com qualidade moradia e bens de uso coletivo indispensáveis a sua reprodução enquanto trabalhadores. Essa dupla exploração (trabalhadores e cidadãos), conjuntamente ao contexto de redemocratização brasileira, daria sentido a uma ampla mobilização de associações e movimentos urbanos nesse período. Para Cardoso (2008), contudo, essa explicação para a gênese da mobilização de movimentos urbanos se replicou acriticamente, como uma fórmula comum a todos os movimentos urbanos.

A ideia de uma classe trabalhadora urbana ganha contornos mais específicos com a análise das lutas urbanas da classe trabalhadora. Não se trata de mero jogo de palavras, mas a ideia de que o trabalhador, na atual fase do capitalismo, mais do que proletário fabril, constitui um tipo de formação de classe urbana "fragmentado e dividido, múltiplo em suas aspirações e necessidades, em geral itinerante, bem mais desorganizado e fluido do que solidamente implantado" (HARVEY, 2014, p. 17), não é suficiente para explicar o caráter e o conteúdo das lutas sociais. Dito de outra maneira, o fato de haver uma condição urbana daquilo que se define como classe trabalhadora não invoca automaticamente um conteúdo urbano da luta de classe.

Explorar esse campo passa por compreender (i) o encadeamento entre a urbanização e as relações sociais de produção e reprodução e (ii) as formações políticas que operam os próprios conflitos.

Enfrentando o primeiro ponto, Harvey (1982), em artigo de 1976, analisa os conflitos que se estabelecem na produção e uso do ambiente construído (casas, vias, fábricas, escritórios, sistemas de saneamento, estacionamentos, instituições culturais, facilidades educacionais, entre outros) como uma faceta da luta de classes. Ele argumenta que a criação do espaço, recheada de contradições, gera fortes cadeias de conflito. Em sua obra Cidades rebeldes, Harvey (2014) reforça a análise sobre a dimensão urbana das crises capitalistas, a centralidade da urbanização no processo de acumulação do capital e, consequentemente, a importância política da luta pela cidade no enfrentamento do capitalismo.

O segundo aspecto é também fundamental, uma vez que a própria noção de classe vem sendo problematizada nas análises sobre lutas e conflitos sociais. Segundo Bourdieu (2003, p. 136), a “classe no papel” ou a classe teórica não está 
instituída objetivamente, não é classe real "no sentido de grupo e de grupo mobilizado para luta”; para esse autor, é na análise das relações e das ações políticas que se evidencia sua existência efetiva (apesar de a classe teórica ser "provável”). Mesmo considerando a ressalva de Bourdieu, há o risco de que a análise que se sustenta na categoria classe social subsuma outras formas de conflito. São diversificadas as análises da sociologia dos movimentos sociais que relativizam ou negam a abordagem de classe.

Para Melucci (2001, p. 156), muitas explicações sobre ações coletivas se apoiavam na imagem do movimento socialista europeu do século XIX, com ênfase nas condições necessárias para a ocorrência ou não de uma revolução. Em outro polo, ideologia, ciência social, filosofia e práticas políticas orientadas a evitar distúrbios na ordem social (ALONSO, 2009) se articulam, produzindo compreensões negativas sobre as ações coletivas. Movimentos coletivos e protestos passam a ser identificados como indicadores de disfunção social, promovidos por impulsos inconscientes ou irracionais presentes na multidão ou nas massas (CHAZEL, 1995), representando uma oposição à expansão da democracia representativa.

Na interpretação da conflitualidade social, a tendência que associava protestos e contestação a impulsos psíquicos inconscientes foi fortemente refutada pela corrente da mobilização de recursos e dos processos políticos na sociologia estadunidense, principalmente por Tarrow, Tilly, McAdam, Zald, McCarthy (intitulado McTeam), que demonstraram que as ações coletivas também são marcadas por decisões racionais, objetivas e estratégicas (FLACKS, 2005, p. 49). A tese da irracionalidade da ação coletiva teria sido colocada em xeque pelos "novos movimentos sociais” a partir da década de 1960, como os movimentos feminista, negro ou pacifista, que - sem promover um retorno à classe e ao movimento operário - reforçaram o caráter identitário dos movimentos e suas novas bandeiras, como, gênero, raça, meio ambiente, pacifismo e democracia. As lutas e mobilizações não se orientariam para a tomada do Estado, mas para a ampliação de políticas públicas, as mudanças de caráter cultural (sociabilidade e estilo de vida) e a melhoria da qualidade de vida (distribuição de recursos materiais) e reconhecimento como corpos e sujeitos. Seus atores, jovens de classe média, mulheres (enquanto movimento), negros, profissionais liberais, empreendiam lutas fora dos canais tradicionais de mobilização e representação, como sindicatos e partidos.

A interpretação baseada na mobilização de recursos destaca que a capacidade de empreender lutas vitoriosas se encontra, muitas vezes, em variáveis associadas à organização, como grau de burocratização, divisão do trabalho entre seus membros e recursos mobilizados, como número de militantes, recursos financeiros e rede de apoiadores (ALONSO, 2009). A corrente dos processos políticos enfatiza os 
processos de gênese de movimentos sociais, a noção de ciclos de protestos e a conexão entre ações coletivas e o contexto político mais amplo, que inclui a noção de “oportunidades políticas” para a mobilização de atores coletivos. As escolhas dos atores se refletem tanto nos preparativos de uma ação e nos repertórios mobilizados como nas possíveis reações contrárias à ação, indicadas pelo grau de repressão e alcance da mobilização ou protesto.

Nesse sentido, uma ação coletiva ou um protesto podem fracassar ou ter um fim em si mesmos, em razão de se efetuarem no âmbito local, particular e restrito. Em outras ocasiões, podem representar articulações mais amplas entre organizações ou bandeiras de lutas, tendo caráter nacional ou internacional (TARROW, 2009). É nessa perspectiva que reside a crítica às interpretações sobre mobilização baseadas exclusivamente em um conflito a priori entre classes sociais (pois subestimariam as condições que efetivamente produzem o engajamento em lutas políticas) e na reivindicação da importância da análise dos confrontos como recursos empíricos para a compreensão do fenômeno da ação coletiva, sejam protestos, movimentos sociais ou revoluções. Assim, em grande medida, esses autores contribuíram para conferir centralidade à ação, como fenômeno social, nas análises sobre movimentos sociais. Desse modo, eles propõem um quadro teórico que visa mapear processos de confronto político (McADAM; TARROW; TILLY, 2009), considerando as diferentes condições institucionais, oportunidades políticas e capacidades organizativas (capacidades concretas de mobilização e de escolhas de repertórios) de cada movimento e seus contextos. Essa perspectiva reforça a necessidade de analisar as formas concretas de mobilização política, de produzir material empírico que fundamente a interpretação da ação coletiva, com vistas a evitar os limites da explicação funcional (PERISSINOTTO, 2011) que leva a concluir que a classe trabalhadora entra em confronto político porque é explorada ou, ainda mais teleologicamente, que a relação entre capital e trabalho produziria uma espécie de “inscrição genética” para luta que dependeria apenas de sua tomada de consciência. Apesar disso, há, sem dúvida, outros limites a essa abordagem.

A ênfase na variável oportunidades políticas deve ser tratada com cautela, para não incorrer na substituição das condicionantes econômicas pelas condicionantes políticas na explicação da gênese e no desenvolvimento de ações coletivas e movimentos sociais (ABERS; BÖLOW, 2011) ou no aprisionamento à análise conjuntural, valorizando excessivamente o modus operandi dos movimentos sociais e negligenciando os processos políticos macroestruturais e de longo alcance (ALONSO, 2009, p. 53). Jasper (2016) enfatiza a pouca importância que a corrente dos processos políticos dá à cultura e aos vínculos identitários e todo o investimento mobilizatório necessário para manter um movimento coeso, mediando inúmeros 
conflitos internos na produção de causas e de conteúdos em comum, seja de caráter simbólico, moral ou emotivo. Vale ainda ressaltar as possíveis articulações entre as dimensões identitárias e de classe das lutas sociais, tal como bem ilustrado no debate entre Fraser e Honneth (2003), fundamentado nas categorias redistribuição e reconhecimento.

O que se quer destacar aqui é que uma explicação para a ocorrência de ações coletivas e de protestos tem que se dedicar, em alguma medida, à superação da dicotomia entre estrutura e agência, ou, pelo menos, à compreensão de que as motivações para o envolvimento em processos conflitivos, que, muitas vezes, contêm a possibilidade de repressão e violência, se desenvolvem em decorrência de múltiplas razões, desde macroprocessos, como mudanças institucionais e políticas, modernização e crises societárias e econômicas, até a construção de relações face a face entre atores, num âmbito local e microssociológico pelos mais variados motivos. No nosso caso, significa interpretar a cidade como continente, mas também como conteúdo de lutas, protestos e mobilizações, considerando, ao mesmo tempo: (i) a inserção dos agentes de confronto - situação, posição e distinção - na estrutura e nas relações sociais contraditórias de produção e reprodução urbanas e (ii) os processos políticos, os recursos de mobilização, as identidades e os fins visados pelos agentes.

2. Eventos de protesto, ciclo de protesto e conflitos: metodologia de pesquisa, unidades de análise e categorias de interpretação

Inicialmente, o Observatório de Conflitos Urbanos de Curitiba adotou a metodologia desenvolvida pelo projeto Mapa de Conflitos Urbanos do Rio de Janeiro. Foram registrados protestos (inicialmente denominados conflitos) em Curitiba e em mais doze municípios metropolitanos, classificados em cinco categorias básicas: (i) o objeto de conflito, (ii) a forma de manifestação do conflito, (iii) os agentes do conflito (coletivo mobilizado e a instituição ou grupo reclamado), (iv) os locais de origem e manifestação e (v) a data de ocorrência do evento. As informações foram obtidas em registros de jornais diários de grande circulação (Gazeta do Povo e Paraná Online), bem como em mídia independente, redes sociais, portais de notícia, programas de rádio (Banda B) e jornais locais dos municípios da RMC. Contudo, no decorrer do desenvolvimento da pesquisa, a metodologia utilizada passou a evidenciar alguns limites diante da complexidade dos protestos.

Um deles decorre das próprias fontes de informação. Os meios de comunicação, em consequência das posições políticas que adotam, operam seleções sobre quais eventos “merecem” ser destacados nos jornais, restringindo áreas de cobertura e temas, omitindo informações ou apresentando vieses relativos à descrição 
do evento (SILVA et al., 2015). Reconhecer esses limites é importante para problematizar as fontes, sem, porém, inviabilizá-las, considerando que um dos objetivos de uma coleta ampla e diversa sobre os conflitos é evitar o viés de seleção presente em estudos de caso, pois, apesar dos ganhos descritivos dos eventos, por vezes generalizam-se particularidades que não são representativas do conjunto das manifestações. Silva et al. (2015) também destacam que fontes de jornais têm sido amplamente utilizadas em pesquisas sobre ciclos de protestos por serem públicas, permanentes no tempo e de fácil acesso, diferentemente, por exemplo, de fontes policiais. Nas notícias de rádios ou portais de notícias, procura-se registrar, quando disponíveis, as informações de entrevistas realizadas diretamente com os agentes envolvidos, com o propósito de aprimorar sobretudo a descrição dos objetos de conflito. Por fim, busca-se minimizar os possíveis vieses por meio da triangulação de diferentes fontes jornalísticas e da complementação com dados obtidos nas redes sociais dos agentes (lideranças e movimentos sociais) e por meio de observações diretas.

Outro limite importante refere-se à estrutura tabular (bidimensional) do banco de dados, que permitia o registro unitário de protestos, limitando múltiplos registros para o mesmo evento. 0 ciclo de protestos e manifestações de junho de 2013 evidenciou fortemente a necessidade de renovar os instrumentos de análise com maior flexibilidade e capacidade de viabilizar novas correlações, como o registro de múltiplos agentes e objetos de conflito, a identificação de sequências de eventos vinculados a um mesmo conflito ou a análise da dinâmica do conflito com base em seus eventos individualizados, na diversificação das formas de manifestação e de envolvimento dos agentes. Para superar essa lacuna, foi necessário modificar a estrutura tabular do banco de dados, substituindo-a pela estrutura relacional, conforme se observa na Figura 1.

Adicionalmente, a pesquisa passou a incorporar, nos registros de eventos, categorias que permitiam associá-los em cadeias de protestos, contribuindo para aprimorar as análises das estruturas de mobilização, do comportamento de movimentos sociais e das mudanças nos seus repertórios de ação. Além da indiferenciação entre eventos de protesto e conflitos urbanos propriamente ditos, precisavam ser superadas as restrições para registro de múltiplos atores e para a categorização de objetos de conflitos e formas de manifestação, para citar apenas alguns exemplos. As principais inovações metodológicas propostas desenvolvidas ao longo da pesquisa dizem respeito a duas ordens de questões: (i) as unidades de análise e (ii) as categorias de interpretação. 


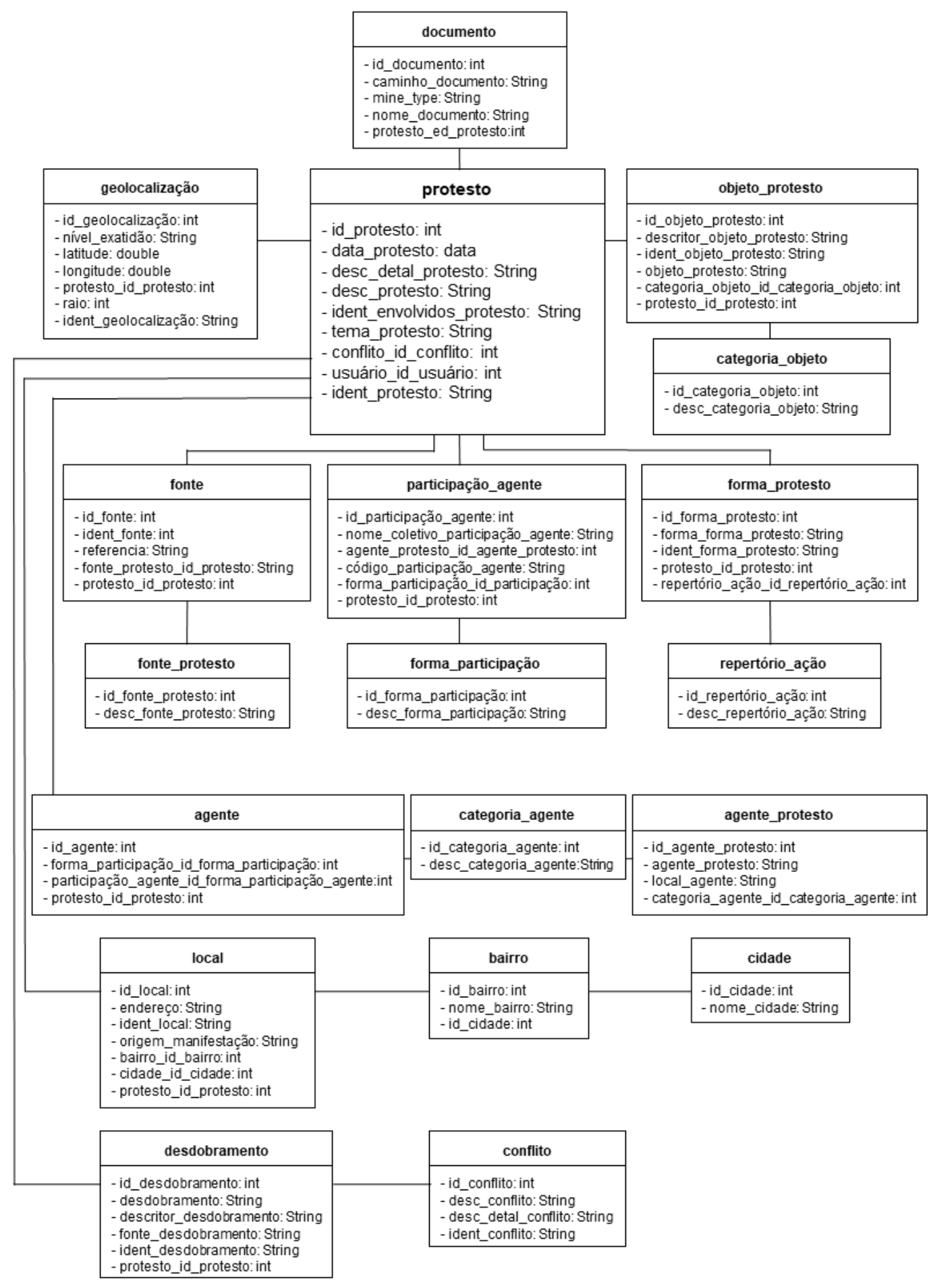

Figura 1. Estrutura relacional do banco de dados de conflitos urbanos em Curitiba Fonte: Observatório de Conflitos Urbanos de Curitiba (2020). 
A avaliação dos protestos catalogados nos dois primeiros anos da pesquisa, da revisão teórica sobre ação coletiva, do trabalho de Silva, Araujo e Pereira (2011) e da metodologia do Observatoire sur l'activité conflictuelle das cidades de Quebec e Montreal, no Canadá, integrantes da rede de observatórios, foi o ponto de partida para a elaboração de uma nova proposta de banco de dados, com um conjunto de variáveis que apresenta como unidade de análise o protesto. A partir dela, conectam-se as outras variáveis, que possuem associações múltiplas, conforme apresentado na Figura 1.

Os eventos de protesto são registrados de acordo com cada manifestação que ocorre no espaço público, e o conflito urbano é o litígio que dá causa à manifestação e pode estar associado a um conjunto de eventos articulados com o mesmo objeto. Essa diferenciação permite a classificação integrada dos eventos em "rede" de protestos, os quais, por sua vez, podem agregar-se em conflitos com maior durabilidade e permanência ao longo do tempo. A análise relacional dos protestos desencadeados em "redes" permite registrar a diversidade dos objetos, os repertórios de ação e os possíveis desdobramentos, identificando ações contenciosas com possível uso de violência. Proporciona, ainda, uma análise mais ampla das contradições inerentes, do campo de ação coletiva, da lógica dos movimentos sociais e de suas articulações em rede.

Nesta perspectiva, avalia-se a importância da construção de um instrumento de pesquisa que registra e cataloga, ao longo do tempo, a diversidade, a flexibilidade e a mutabilidade existentes nas manifestações, tendo em vista que, quando analisadas isoladamente, podem passar despercebidas.

Com a análise do ciclo de protestos, é possível perceber, por exemplo, que conflitos por moradia em Curitiba, geralmente associados com ações de ocupação de terras ou prédios, não se limitam a essa forma de ação. Sua mobilização alcança os espaços de participação em esferas institucionais, como audiências públicas, a proposição de diretrizes no Plano Diretor, a pressão pela aprovação do projeto de lei que regulamenta o aluguel social, a participação em fóruns nacionais e a proposição de ações judiciais.

A análise em rede das manifestações também permite ampliar a compreensão sobre a participação de múltiplos agentes e as conexões existentes entre coletivos, instituições e grupos sociais, nas diversas escalas de ação. Diferentemente da metodologia do Observatório de Conflitos Urbanos do Rio de Janeiro, que identifica os atores-polo do conflito em categorias gerais, considera-se que há diversas formas de participação dos agentes. Assim, além de nomeá-los, procede-se a uma classificação em duas dimensões: o tipo do agente e a forma de participação. Nessa segunda forma de classificação, os agentes podem ser: (i) instigadores - que tomam a iniciativa da ação coletiva; (ii) reclamados - a quem se dirige a reivindicação; (iii) 
apoiadores - que participam de forma direta ou indireta no protesto, mediante apoio financeiro, intelectual ou operacional de suporte à manifestação; (iv) opositores - aqueles que se opõem à reivindicação; (v) afetados - os que não têm necessariamente relação com o conflito, mas são afetados pela ação coletiva de modo direto e/ou indireto. Os agentes podem, ainda, ser classificados em mais de uma forma de participação (por exemplo, opositores e reclamados).

O ciclo de protestos de 2013 também tornou mais evidente que a classificação dos objetos de protesto em categorias temáticas preestabelecidas poderia ofuscar a quantidade e a diversidade das reivindicações em cada manifestação. Assim, os objetos passaram a ser descritos de maneira o mais próxima possível do discurso dos agentes, incluindo, além das categorias classificatórias, frases de descrição sumária, com o objetivo de registrar o(s) objeto(s) de protesto.

No que tange aos repertórios de ação, a estrutura do banco de dados considera a possibilidade de inclusão de novas categorias, criadas e incorporadas pelos manifestantes e que podem ser reproduzidas em diferentes contextos em função da sua eficácia. Essa opção reconhece que os movimentos sociais procuram criar, ao longo do tempo, novas formas que desafiem os códigos instituídos e surpreendam o oponente (McADAM; TARROW; TILLY, 2009).

As principais diferenças entre as duas metodologias dizem respeito à flexibilização da forma de registrar e catalogar o material empírico, com a inserção no Observatório de Curitiba da definição do protesto como unidade de análise e as possíveis associações de protestos em rede como parte integrante de um mesmo conflito. Destaca-se ademais a inclusão de novas categorias como os "desdobramentos” e a "ação contenciosa”, que visam caracterizar as consequências pós-manifestação, a ocorrência ou não de confronto e a constatação de desdobramentos decorrentes da pressão exercida pela ação coletiva. Por fim, incorporou-se o registro das coordenadas geográficas do local de manifestação e de origem do protesto, o que permite espacializar as informações sobre os protestos.

\section{Análise dos protestos em Curitiba: hipóteses para interpretação dos conflitos urbanos}

No período compreendido entre os anos de 2013 e 2019, 707 eventos foram registrados e mapeados, predominando, em termos de objeto, protestos relacionados a Estado, governo e democracia (25,46\%), Trabalho e direitos trabalhistas (17,82\%), Transporte, trânsito e circulação (10,89\%), seguido de Educação (9,62\%), Gênero, raça e diversidade (6,93\%), Segurança pública (6,36\%) e Moradia (5,94\%), conforme Figura 2. Somados, eles correspondem a 83,02\% dos protestos e contribuem, inclusive, para o questionamento de ideias amplamente disseminadas no "mito da cidade modelo" (OLIVEIRA, 2011). 


\begin{tabular}{|c|c|c|c|c|c|c|c|c|c|c|c|c|c|c|c|}
\hline \multirow[b]{2}{*}{ Motivação x Ano } & 2013 & \multicolumn{2}{|c|}{2014} & \multicolumn{2}{|c|}{2015} & \multicolumn{2}{|c|}{2016} & \multicolumn{2}{|c|}{2017} & \multicolumn{2}{|c|}{2018} & \multicolumn{2}{|c|}{2019} & \multirow[b]{2}{*}{$\begin{array}{l}\bar{\pi} \\
\stackrel{0}{0}\end{array}$} & \multirow[b]{2}{*}{$\%$} \\
\hline & 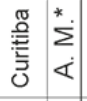 & 胥 & $\begin{array}{l}\sum^{*} \\
\dot{<}\end{array}$ & 胥 & $\sum_{\dot{\Sigma}}^{*}$ & 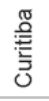 & $\sum_{\dot{L}}^{*}$ & 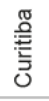 & $\begin{array}{l}* \\
\Sigma \\
\dot{\Sigma}\end{array}$ & 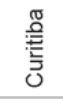 & $\sum_{<}^{*}$ & 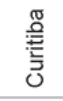 & $\sum_{<}^{*}$ & & \\
\hline Estado, governo e democracia & 0 & 0 & & & & & O & & & & ○ & & O & 180 & 25,46 \\
\hline Trabalho e direitos trabalhistas & 0 & O & 0 & 0 & ○ & & O & & 0 & & & & 0 & 126 & 17,82 \\
\hline Transporte, trânsito e circulação & 0 & O & 0 & 0 & 0 & & 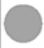 & & & & O & & 0 & 77 & 10,89 \\
\hline Educação & 0 & 0 & & ○ & ○ & & ○ & & & & - & & O & 68 & 9,62 \\
\hline Gênero, raça e diversidade & ○ & & & ○ & & O & & & & & & & 0 & 49 & 6,93 \\
\hline Segurança pública & ○ & O & 0 & - & & & O & ○ & 0 & & ○ & & O & 45 & 6,36 \\
\hline Moradia & 0 & ○ & & 0 & O & ○ & O & ○ & & ○ & 0 & & O & 42 & 5,94 \\
\hline Saúde & ○ & 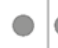 & 0 & ○ & & ○ & & O & 0 & & ○ & & & 33 & 4,67 \\
\hline Questões fundiárias & & ○ & & ○ & & ○ & & & & O & & O & ○ & 12 & 1,70 \\
\hline $\begin{array}{l}\text { Água, esgoto, drenagem e } \\
\text { resíduos sólidos }\end{array}$ & ○ & ○ & & & & & ○ & & 0 & & ○ & & O & 12 & 1,70 \\
\hline Vizinhança & 0 & 0 & 0 & ○ & 0 & & O & & & & & O & & 10 & 1,41 \\
\hline Parques, jardins e florestas & & - & & & & & & ○ & & ○ & & O & & 10 & 1,41 \\
\hline Acesso e uso do espaço público & ○ & & & & & & & & & O & & O & & 9 & 1,27 \\
\hline Energia e gás & & 0 & O & & & O & & & & O & & & & 6 & 0,85 \\
\hline Legislação urbana & 0 & & & & & & & 0 & & & & & & 2 & 0,28 \\
\hline Outros & 0 & 0 & & & & ○ & & ○ & & & & & 0 & 26 & 3,68 \\
\hline Subtotal & \begin{tabular}{l|l}
36 & 10 \\
\end{tabular} & 29 & 93 & 35 & 15 & 87 & 21 & 64 & 9 & 181 & 25 & 163 & 23 & \multirow{2}{*}{707} & \multirow{2}{*}{100} \\
\hline Total & 46 & \multicolumn{2}{|l|}{38} & \multicolumn{2}{|c|}{50} & \multicolumn{2}{|c|}{108} & \multicolumn{2}{|c|}{$73^{\star \star}$} & \multicolumn{2}{|c|}{206} & \multicolumn{2}{|c|}{186} & & \\
\hline & $\begin{array}{l}\left({ }^{\star}\right) \mathrm{Agl} \\
\left({ }^{\star \star}\right) \mathrm{An} \\
\text { protes }\end{array}$ & $\begin{array}{l}\text { lomer } \\
\text { no cor } \\
\text { stos }\end{array}$ & $\begin{array}{l}\text { rado } \\
\mathrm{m} m\end{array}$ & met & $\begin{array}{l}\text { tropc } \\
\text { festa }\end{array}$ & & & port & & s me & em & uant & ide $t$ & otal de & \\
\hline
\end{tabular}

Figura 2. Protestos em Curitiba e Aglomerado Metropolitano entre 2013 e 2019 Fonte: Observatório de Conflitos Urbanos de Curitiba (2020).

Uma das etapas da metodologia foi a inserção de novas categorias, como "Trabalho e direitos trabalhistas", "Estado, governo e democracia”, "Gênero, raça e diversidade”, que inicialmente não integravam o mapeamento de protestos urbanos, por serem considerados conflitos sociais. No entanto, como o objetivo final é analisar a conflituosidade social na RMC, e esses protestos são manifestações expressivas na cidade, foram inseridas como parte do projeto. Se analisarmos as duas primeiras categorias, "Trabalho e direitos trabalhistas" e "Estado governo e democracia”, observa-se que elas estão interligadas e associadas às diversas reformas e arrochos trabalhistas, especialmente de servidores públicos. Os ciclos de protestos de junho de 2013, os protestos contra a ex-presidenta Dilma Rousseff e o presidente Michel Temer, ocorridos entre 2015 e 2016, e os atos em defesa da Operação Lava 
Jato ou de reivindicação da liberdade do ex-presidente Lula, realizados entre 2018 e 2019, são os principais eventos registrados na categoria "Estado, governo e democracia”. Os protestos de natureza política também foram muito frequentes e alimentados pela instabilidade política do país.

Observando a categoria que envolve a mobilidade urbana, os temas de segurança e infraestrutura viária somam $72 \%$ dos eventos registrados. Em relação às vias públicas, as principais reivindicações dizem respeito à pavimentação, à sinalização e a infraestruturas de segurança (semáforos, passarelas, trincheiras, acessos, lombadas, redutores de velocidade e revisão de alguns cruzamentos considerados "trevos da morte"). No caso de promessas não cumpridas, ocorreram manifestações criativas, com repertórios do tipo bolo de aniversário e "Parabéns para você", além da pichação de ruas e do fechamento delas com lixo, da panfletagem em cruzamentos e de mutirão comunitário para o fechamento de buracos. Os acidentes com mortes ou atropelamentos, entretanto, são a motivação para o maior número de protestos. Neste caso, as formas de protesto mais usuais são a queima de pneus, o fechamento de ruas e a implantação de faixas e cruzes lembrando as vítimas. As duas situações são postas em prática por familiares e vizinhos das vítimas ou por moradores do bairro diretamente afetados pela precariedade urbana.

Apenas 15\% das reivindicações envolvendo mobilidade estão associadas com tarifa, trajeto e qualidade do transporte coletivo de Curitiba e Região Metropolitana ou ciclomobilidade. Parte desses protestos demanda investimentos em infraestrutura e melhores serviços; a outra parte, contudo, contesta as políticas urbanas adotadas pelo poder público e reivindica a inversão de prioridades e também uma nova compreensão sobre mobilidade urbana. Claramente, neste tema, há diferenças em termos de organização e mobilização dos agentes. Nos eventos relacionados à segurança e infraestrutura viária, são mais raras as mobilizações de longo termo, ao passo que, no tocante à constituição de movimentos sociais, são mais amplos, tal como acontece em alguns eventos relativos aos temas do transporte público e da ciclomobilidade.

Com relação aos protestos em torno do tema "Moradia”, observa-se um amplo leque de repertórios de ações coletivas, desde ações contenciosas em situações de despejo forçado até reivindicações de participação em estruturas institucionais ou de implementação de projetos. As reivindicações de caráter institucional também revelam o compartilhamento de projetos políticos com agentes de outras escalas de ação (regionais e nacionais). O coletivo mobilizado varia bastante, mas consiste, em sua maioria, de moradores que se sentem ameaçados por remoções ou por intervenções do poder público. Em menor escala incluem-se os movimentos sociais 
nacionais, articulados em rede, e os movimentos locais, que muitas vezes militam em diversos temas, caracterizando uma atuação ampla pelo direito à cidade.

Também é possível verificar correlação entre o objeto do protesto e os agentes mobilizados. Em diversas manifestações restritas à precariedade de infraestrutura (relacionadas preliminarmente como "consumo" da cidade), identificam-se com mais frequência entre os agentes instigadores grupos de moradores, com menor recorrência de movimentos sociais ou organizações mais institucionalizadas.

Quanto à localização, Curitiba concentra cerca de $84 \%$ dos protestos registrados, seguido pelos municípios de Araucária, São José dos Pinhais e Colombo, que concentram, juntos, $11 \%$ dos conflitos no período. Poucos eventos foram registrados nos outros oito municípios analisados, com uma média de menos de uma ocorrência por ano. É importante ressaltar que Curitiba possui maior cobertura jornalística e recebe maior atenção dos meios de comunicação. Os limites das fontes de informação são reconhecidos na pesquisa e impõem a necessidade de ressalva em relação às conclusões sobre distribuição espacial. Além das pautas mais pontuais, verificam-se grandes eventos associados à política nacional, protestos pelo transporte (Jornadas de Junho de 2013), a primavera estudantil, com a ocupação de mais de cem escolas públicas estaduais, protestos contra a lei de congelamento dos investimentos sociais e protesto dos professores (conhecido como a batalha do Centro Cívico). Os demais municípios concentram protestos ligados, em sua maioria, à infraestrutura e à melhoria dos bairros.

A espacialização dos protestos propiciou igualmente a percepção das diferenças associadas aos objetos. No tema "Moradia", há clara predominância de manifestações localizadas em bairros periféricos, especialmente aqueles com maior déficit de infraestrutura e precariedade da posse. Em contraponto, as manifestações em defesa de espaços públicos verdes, como praças e jardinetes, são realizadas em bairros predominantemente residenciais de classe média e alta, próximos às regiões mais centrais.

A análise do banco de dados evidencia uma segmentação social, associada ao tipo de protesto e à sua localização na cidade (Mapa 1). $O$ anel central é o palco dos mais diversos eventos, seja pelo seu valor simbólico, seja pela localização próxima a prédios públicos, envolvendo manifestações classificadas em todas as categorias. Alguns lugares da região central de Curitiba se destacam como pontos de referência para manifestações, como a rua das Flores, a Boca Maldita, a praça Tiradentes, a praça Santos Andrade, a praça 19 de Dezembro e a praça Rui Barbosa. Na periferia, as reivindicações apontam para as precárias condições de vida urbana e, em bairros próximos ao centro, predominam demandas por reconhecimento de formas alternativas de apropriação do espaço público, como a qualidade dos espaços verdes. 


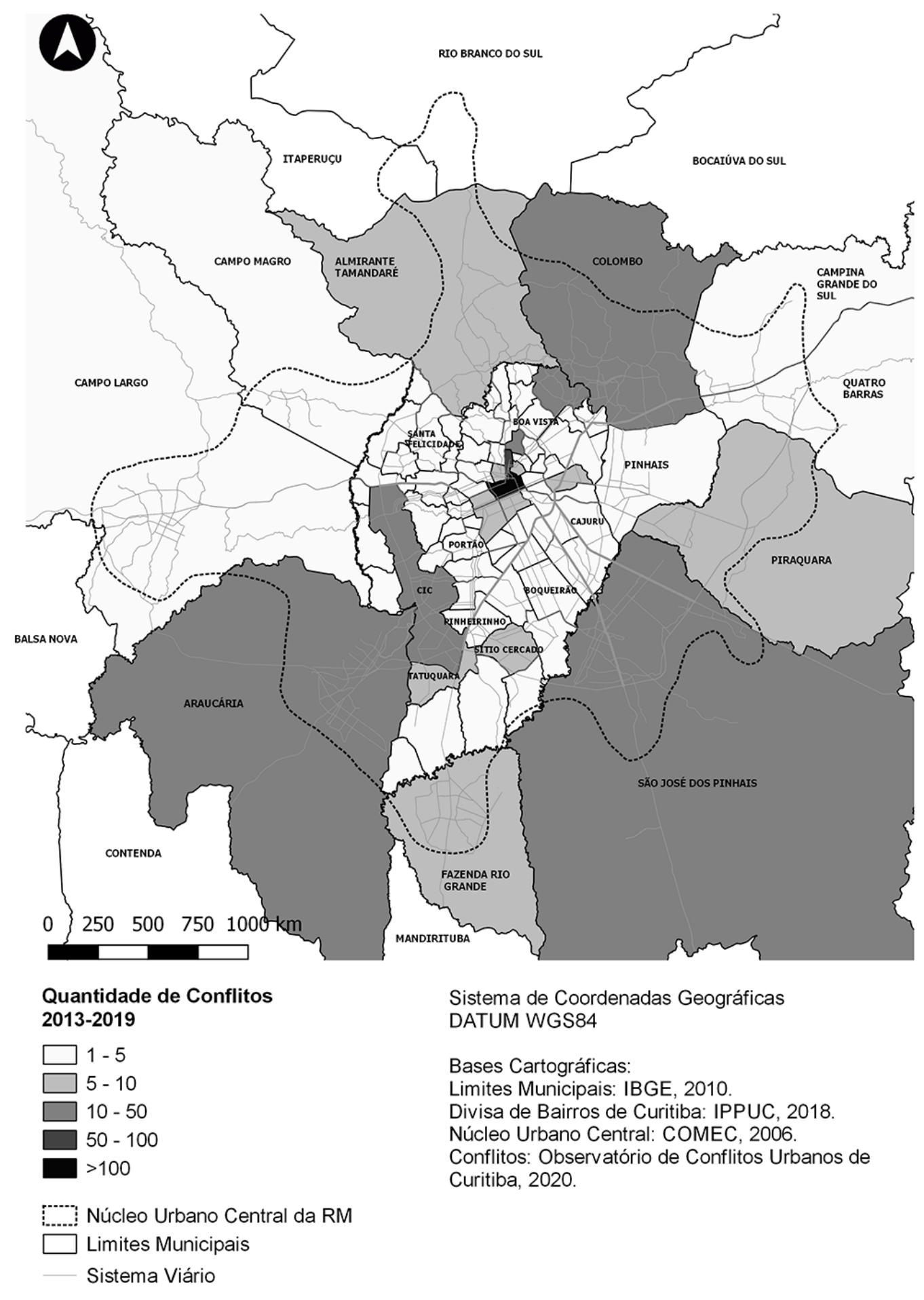

Mapa 1. Mapa de conflitos urbanos por municípios metropolitanos e bairros de Curitiba entre 2013 e 2019

Fonte: Observatório de Conflitos Urbanos de Curitiba (2020). Elaborado por SIMIONATO, N. 
Finalmente, apesar da expressividade, em termos quantitativos, dos protestos relacionados à conjuntura nacional, dois destaques são importantes. O primeiro se refere à articulação escalar e às especificidades locais das manifestações de caráter nacional. As Jornadas de Junho de 2013, iniciadas com manifestações do Movimento do Passe Livre contrárias ao aumento da tarifa de ônibus, tiveram importantes desdobramentos para a política municipal e metropolitana de transporte coletivo, com redução da tarifa, desintegração do transporte metropolitano, criação de CPI na Câmara dos Vereadores de Curitiba e investigação de desvios na licitação municipal por parte do Tribunal de Contas do Estado. Os atos contra a política nacional de Reforma do Ensino Médio, que ocorreram no ano de 2016, influenciados por manifestações de estudantes secundaristas que vinham ocorrendo desde $2015^{4}$, conhecidos como Primavera Secundarista, tiveram a primeira ocupação de escola, em nível nacional, no município de São José dos Pinhais, com implicação na adesão expressiva do movimento estudantil secundarista no estado do Paraná e significativa multiplicação dos casos de escolas ocupadas na RMC. No caso dos atos em defesa da Operação Lava Jato e de reivindicação de liberdade para Lula, a localização do Tribunal Federal em Curitiba e a prisão do ex-presidente na sede da Polícia Federal da capital paranaense estruturaram espaços permanentes de protesto (Acampamento Lava Jato, em frente ao Tribunal Federal, e Acampamento Lula Livre, em frente à Polícia Federal). Tais casos ilustram o rebatimento e a associação dos protestos motivados pela conjuntura ou por políticas públicas nacionais que ecoam e se reconfiguram localmente

O segundo destaque é relativo às categorias que concentram de modo mais expressivo as manifestações de caráter local. Transporte, com ênfase nas questões de segurança viária, assim como segurança pública e moradia, representam cerca de $55 \%$ dos protestos que reivindicam políticas e ações municipais ou que opõem agentes locais.

\section{Conclusões e categorias de interpretação}

Apesar da quantidade significativa de registros de protestos, as análises ainda têm apontado mais problematizações do que conclusões. As evidências empíricas e as interpretações teóricas que salientam a questão urbana nas lutas sociais permitem apontar, contudo, que os conflitos urbanos, como expressão da conflitualidade social, são fenômenos importantes e objeto destacado para a reflexão

4. Em 2015 e início de 2016, ocupações de escolas já haviam ocorrido em outros estados, como São Paulo, Rio de Janeiro e Rio Grande do Sul, relacionadas às manifestações contra políticas estaduais de educação e à Proposta de Emenda Constitucional de limitação das despesas da União (PEC-241). 
sobre as dinâmicas e as relações sociais. Assim, a proposta deste trabalho, além de analisar os conflitos urbanos em Curitiba e no Aglomerado Metropolitano, foi apresentar categorias e metodologia capazes de contribuir para aprofundar o conhecimento sobre as lutas sociais urbanas e sua inserção na dinâmica mais geral da conflitualidade social. A reflexão crítica sobre a prática de pesquisa do Observatório de Conflitos Urbanos de Curitiba pode fornecer referenciais para outros observatórios e pesquisadores que se debruçam sobre o tema.

A análise dos resultados evidencia algumas das questões problematizadas neste texto. Os protestos acionam, em diferentes medidas, eventualmente de modo articulado, demandas pela qualificação (melhorias em infraestrutura e serviços), apropriação (reconhecimento de usos) e transformação (modificação dos processos de produção) dos espaços urbanos, denotando o encadeamento complexo entre a urbanização e as relações sociais de produção e reprodução do espaço urbano. Essa economia política do espaço aponta para uma compreensão das lutas urbanas decorrente tanto do consumo do espaço (valor de uso) como de seu modo de produção. Essas dimensões, já presentes criticamente nas interpretações de Lefebvre (2006) e Harvey $(1982,2014)$, em especial na acepção do direito à cidade destacado por esses autores, revelam que produção e consumo, ainda que não se evidenciem nas práticas espaciais como recortes do mundo sensível, pois as ações coletivas concretas não dissociam necessariamente essas dimensões, são categorias que podem auxiliar na interpretação dos conflitos urbanos. Neste sentido, os dados apresentados reforçam um argumento já bastante exaustivo na literatura nacional sobre a articulação entre precariedade dos serviços urbanos e lutas sociais, consagrado no conceito de espoliação urbana de Lúcio Kowarick (1979), formulado na década de 1970 e que destacava a crueza do capitalismo periférico, sobretudo na periferia dos grandes centros urbanos. Esse argumento se mantém em grande medida nos diagnósticos sobre espaço urbano brasileiro em razão de, passados quarenta anos de sua redação, ainda não termos superado as bases materiais (mínimas) de uma estrutura de classe extremamente desigual (MARICATO, 1995; 2011; ROLNIK, 1997). Não obstante o prisma das contradições urbanas como variável explicativa seja carregado com um pressuposto normativo sobre a emergência de movimentos sociais (CARDOSO, 2008), este tem sido um importante quadro interpretativo (frame) e mobilizador de um conjunto amplo de atores em torno da agenda política pelo direito à cidade, que objetivamente tem garantido certas conquistas durante esse período.

A ideia de que esses conflitos estariam relacionados às dinâmicas e às condições desiguais de apropriação do espaço remete, no entanto, a outro debate teórico relevante na interpretação das lutas por justiça social. Se a leitura de tais 
contradições confere centralidade ao problema da redistribuição, importa reconhecer que o mapeamento dos conflitos em Curitiba também apontou para a importância de registrar os conflitos sociais e culturais referentes ao "reconhecimento da diferença” (FRASER, 2006) que mobiliza as lutas de grupos por etnicidade, envolvendo raça, gênero, diversidade e religião. Além dos aspectos econômicos, as evidências empíricas da conflitualidade indicam objetos, agentes e formas de disputa que ampliam o ideário de justiça social pela superação da desigualdade socioeconômica. Do debate entre Fraser e Honneth (2003) depreende-se a compreensão das lutas sociais apoiada pelas categorias reconhecimento e redistribuição, confrontando e articulando as dimensões identitárias e econômicas e colocando em questão as interpretações que restringem conflitos à luta de classes ou à conjuntura e às oportunidades políticas.

Os protestos em torno da crise política com ameaças à democracia e à governabilidade do país; da reivindicação quanto à diversidade de gênero, nas marchas da Diversidade e das Vadias; e do direito à expressão e manifestação cultural no Carnaval, entre outros eventos, são exemplos de conflitos sociais que foram adicionados ao longo do tempo no mapeamento local - ainda que tais demandas, por vezes, tenham caráter nacional, variando as escalas e a interação entre os agentes, os movimentos e as pautas políticas.

Portanto, além da necessária consideração dos aspectos que implicam as condições de desigualdade material, evidenciam-se as lutas que denunciam a dominação cultural. Assim, Consumo, Produção e Reconhecimento podem constituir categorias explicativas dos conflitos urbanos.

A despeito dos limites epistemológicos da articulação teórica proposta, compreende-se que a incorporação de algumas categorias analíticas permite ampliar o entendimento sobre a relação dinâmica entre as lutas sociais e a transformação da sociedade e do espaço que lhe é correlato.

No caso de Curitiba, ao analisar de modo articulado os agentes dos protestos, os objetos de reivindicação e as formas de ação coletiva, tornam-se nítidas as distinções presentes no interior das manifestações e o caráter simbólico dos lugares, dos sentidos polissêmicos e da ação coletiva em rede, mostrando a complexidade dessas relações e dos agentes sociais. Acima de tudo, as motivações que se concentram em torno dos objetos de moradia e transporte questionam a noção de cidade modelo, sem conflitos, amplamente divulgada pela Prefeitura de Curitiba e problematizada nas análises de Oliveira (2011) e Sanchez (1997). 


\section{Referências}

ABERS. R.; BÜLOW. M. V. Movimentos sociais na teoria e na prática: como estudar o ativismo através da fronteira entre Estado e sociedade? Sociologias, Porto Alegre, ano 13, n. 28, p. 52-84, 2011.

ALONSO, A. As teorias dos movimentos sociais: um balanço do debate. Lua Nova, São Paulo, 76, p. 49-86, 2009.

BEIELER, J. Animated protest mapping. Disponível em: http://johnbeieler.org/. Acesso em: 3 set. 2015.

BOURDIEU, P. O poder simbólico. 6. ed. Rio de Janeiro: Bertrand, 2003.

CARDOSO, R. Movimentos sociais urbanos: balanço crítico. In: SORJ, B.; ALMEIDA, M. H. T. (org.). Sociedade política no Brasil pós-64 [online]. Rio de Janeiro: Centro Edelstein de Pesquisas Sociais, p. 313-350, 2008.

CHAZEL, F. Movimentos sociais. In: BOUDON, R. (org.). Tratado de sociologia. Rio de Janeiro: Zahar, 1995.

ENGELS, F. A situação da classe trabalhadora na Inglaterra. São Paulo: Boitempo, 2008. . Sobre a questão da moradia. São Paulo: Boitempo, 2015.

FLACKS, D. A questão da relevância nos estudos dos movimentos sociais. Revista Crítica de Ciências Sociais, Lisboa, n. 72, p. 45-66, 2005.

FRASER, N. Da redistribuição ao reconhecimento? Dilemas da justiça numa era "pós-socialista”. Cadernos de Campo, São Paulo, n. 14-15, p. 1-382, 2006.

FRASER, N.; HONNETH, A. Redistribution or recognition? A political-philosophical Exchange. London: Verso, 2003.

FORTI, R. (org.). Marxismo e urbanismo capitalista: textos críticos. São Paulo: Ciências Humanas, 1979.

GDELT. Intro. Disponível em: http://gdeltproject.org/. Acesso em: 3 set. 2015.

HARVEY, D. Labour, capital, and class struggle around the built environment in advanced capitalist societies. In: GIDDENS, A.; HELD, D. (org.). Class, power, and conflict: classical and contemporary debates. Berkeley; Los Angeles: UCPress, 1982.

. Cidades rebeldes. São Paulo: Martins Fontes, 2014.

JASPER, J. Protesto: uma introdução aos movimentos sociais. Rio de Janeiro: Zahar, 2016.

KOWARICK, L. A espoliação urbana. São Paulo: Paz e Terra, 1979.

LEFEBVRE, H. O direito à cidade. São Paulo: Centauro, 2006.

MARICATO, E. Metrópole na periferia do capitalismo: ilegalidade desigualdade e violência. São Paulo, jul. 1995. Disponível em: http://www.fau.usp.br/depprojeto/labhab/biblioteca/textos/maricato_metrperif.pdf. Acesso em: 15 jun. 2020.

. Impasse da política urbana no Brasil. Petrópolis: Vozes, 2011.

MARX, K.; ENGELS, F. O Manifesto Comunista. Rio de Janeiro: Contraponto, 1999. 
McADAM, D.; TARROW, S. TILLY, C. Para mapear o confronto político. Lua Nova, São Paulo, n. 76, p. 11- 48, 2009.

MELUCCI, A. A invenção do presente: movimentos sociais nas sociedades complexas. Petrópolis: Vozes, 2001.

MOISÉS, J. A. et al. Cidade, povo e poder. Rio de Janeiro: Paz e Terra, 1982. v. 5. (Coleção Cedec/ Paz e Terra).

OLIVEIRA, D. Curitiba e o mito da cidade modelo. Curitiba: UFPR, 2011.

PERISSINOTTO, R. Considerações sobre o marxismo analítico. In: CODATO, A.; PERISSINOTTO, R. Marxismo como ciência social. Curitiba: UFPR, 2011.

ROLNIK, R. A cidade e a lei - legislação, política urbana e territórios na cidade de São Paulo. São Paulo: Studio Nobel: Fapesp, 1997.

SANCHEZ, F. Cidade espetáculo - política, planejamento e city marketing. Curitiba: Palavra, 1997.

SILVA, M. K; ARAUJO, G. O.; PEREIRA, M. M. Dinâmicas da ação coletiva: análise de eventos de protesto no estudo dos repertórios associativos. In: XXVIII CONGRESSO INTERNACIONAL DA ALAS, 6-11 set. 2011, Recife. Anais [...]. Recife: UFPE, 2011.

SILVA, M. K. et al. Dinâmicas da contestação: transformações nos repertórios de manifestação pública de demandas coletivas no Rio Grande do Sul - 1970 e 2010. In: XVII CONGRESSO BRASILEIRO DE SOCIOLOGIA, 2015, Porto Alegre. Anais [...]. Porto Alegre, 2015.

SIMMEL, G. O conflito como sociação. Tradução: Mauro Guilherme Pinheiro Koury. RBSE Revista Brasileira de Sociologia da Emoção, v. 10, n. 30, p. 568-573, 2011.

TARROW. S. O poder em movimento: movimentos sociais e confronto político. Petrópolis: Vozes, 2009.

TOPALOV, C. Análise do ciclo de reprodução do capital investido na produção da indústria da construção civil. In: FORTI, R. (org.). Marxismo e urbanismo capitalista: textos críticos. São Paulo: Ciências Humanas, 1979. 


\section{José Ricardo Vargas de Faria}

Engenheiro civil, doutor em Planejamento Urbano e Regional pela Universidade Federal do Rio de Janeiro (Ippur/UFRJ), professor do Departamento de Transportes e dos Programas de Pós-graduação em Planejamento Urbano (PPU) e em Políticas Públicas (4P) da Universidade Federal do Paraná (UFPR). Pesquisador do Centro de Estudos em Planejamento e Políticas Urbanas (Ceppur/UFPR) e Líder do Grupo de Pesquisa em Planejamento e Políticas Urbanas da UFPR.

Email: jrvfaria@ufpr.br

ORCID: 0000-0003-2594-3550

Contribuição de autoria: conceituação; curadoria de dados; análise formal; obtenção de financiamento; investigação/pesquisa; metodologia; administração do projeto; recursos; supervisão/orientação; escrita - primeira redação; escrita - revisão e edição.

\section{Simone Aparecida Polli}

Arquiteta e urbanista, mestra e doutora em Planejamento Urbano e Regional pela Universidade Federal do Rio de Janeiro (Ippur/UFRJ), professora do Departamento de Arquitetura e Urbanismo (DEAAU) e do Programa de Pós-graduação em Planejamento e Governança Pública (PPPGP) da Universidade Tecnológica Federal do Paraná (UTFPR). Líder do Grupo de Pesquisa: Cidades, Planejamento e Gestão.

Email: simonep@utfpr.edu.br

ORCID: 0000-0002-9673-592X

Contribuição de autoria: conceituação; curadoria de dados; análise formal; investigação/pesquisa; metodologia; recursos; escrita - primeira redação; escrita revisão e edição. 


\section{Ramon José Gusso}

Cientista social, mestre e doutor em Sociologia Política pela Universidade Federal de Santa Catarina (PPGSP/UFSC). Professor substituto da graduação em Tecnologia em Gestão Pública - Instituto Federal de Brasília, campus Brasília.

Email: prof.ramongusso@gmail.com

ORCID: 0000-0002-5170-3617

Contribuição de autoria: conceituação; metodologia; escrita - primeira; escrita revisão e edição.

Submissão: 26 de maio de 2020.

Aprovação: 3 de setembro de 2020 .

Como citar: FARIA, J. R. V.; POLLI, S. A.; GUSSO, R. J. Observatório de Conflitos Urbanos de Curitiba: metodologia e categorias de análise. Revista brasileira de estudos urbanos e regionais. v. 22, E202035pt, 2020. DOI 10.22296/2317-1529.rbeur.202035pt

Artigo licenciado sob Licença Creative Commons CC BY 4.0.

https://creativecommons.org/licenses/by/4.o/deed.pt_BR 